\title{
Sex-specific effects of subthalamic nucleus stimulation on pain in Parkinson's disease
}

\author{
Olga Khazen, BS, ${ }^{1}$ Marisa DiMarzio, PhD, ${ }^{1}$ Kelsey Platanitis, BS, ${ }^{1}$ Heather C. Grimaudo, MD, ${ }^{2}$ \\ Maria Hancu, ${ }^{1}$ Miriam M. Shao, BS, ${ }^{1}$ Michael D. Staudt, MD, MSc, ${ }^{2}$ Lucy Maguire, MD, PhD, ${ }^{1,2}$ \\ Vishad V. Sukul, MD, ${ }^{2}$ Jennifer Durphy, MD, ${ }^{3}$ Era K. Hanspal, MD, ${ }^{3}$ Octavian Adam, MD, ${ }^{3}$ \\ Eric Molho, MD, ${ }^{3}$ and Julie G. Pilitsis, MD, PhD ${ }^{1,2}$
}

Departments of ${ }^{1}$ Neuroscience and Experimental Therapeutics, ${ }^{2}$ Neurosurgery, and ${ }^{3}$ Neurology, Albany Medical College, Albany, New York

OBJECTIVE Deep brain stimulation (DBS) of the subthalamic nucleus (STN) is known to reduce motor symptoms of Parkinson's disease (PD). The effects of DBS on various nonmotor symptoms often differ from patient to patient. The factors that determine whether or not a patient will respond to treatment have not been elucidated. Here, the authors evaluated sex differences in pain relief after DBS for PD.

METHODS The authors prospectively evaluated 20 patients preoperatively and postoperatively after bilateral STN DBS with the validated numeric rating scale (NRS), Revised Oswestry Disability Index for low-back pain (RODI), and King's Parkinson's Disease Pain Scale (KPDPS) and assessed the impact of sex as a biological variable.

RESULTS The cohort consisted of 6 female and 14 male patients with a mean duration of $11.8 \pm 2.0$ months since DBS surgery. Females were significantly older $(p=0.02)$. Covariate analysis, however, showed no effect of age, stimulation settings, or other confounding variables. KPDPS total scores statistically significantly improved only among males $(p<0.001)$. Males improved more than females in musculoskeletal and chronic subsets of the KPDPS $(p=0.03$ and $p=0.01$, respectively). RODI scores significantly improved in males but not in females $(p=0.03$ and $p=0.30$, respectively). Regarding the NRS score, the improvements seen in both sexes in NRS were not significant.

CONCLUSIONS Although it is well recognized that pain complaints in PD are different between men and women, this study is unique in that it examines the sex-specific DBS effects on this symptom. Considering sex as a biological variable may have important implications for DBS pain outcome studies moving forward.

https://thejns.org/doi/abs/10.3171/2020.6.JNS201126

KEYWORDS deep brain stimulation; subthalamic nucleus; Parkinson's disease; pain; sex differences; functional neurosurgery

$\mathrm{D}$ EEP brain stimulation (DBS) for Parkinson's disease (PD) is a well-recognized treatment that provides significant improvements in motor function. ${ }^{1}$ The impact of DBS on nonmotor symptoms, which are common at all stages of the disease and a major cause of disability, is less well described. ${ }^{2,3}$ Nonmotor symptoms can significantly affect quality of life (QOL) and include pain as well as autonomic and mood symptoms. The management of nonmotor symptoms can be difficult because the mechanisms are not fully understood, and the symptoms are generally insensitive to dopaminergic therapy or sometimes worsen with its use. ${ }^{4}$ Furthermore, whether demo- graphic factors, specifically sex, alter subthalamic nucleus (STN) DBS nonmotor outcomes has not been investigated. Independent of DBS, the effects of sex on nonmotor symptoms in PD have been investigated in one large series. Specifically, Martinez-Martin et al. evaluated the prevalence and severity of nonmotor symptoms by sex in an international sample of $951 \mathrm{PD}$ patients using the nonmotor symptoms scale and found that the nonmotor symptoms most commonly documented in females are pain, anosmia, ageusia, weight change, diaphoresis, and mood changes; these are in contrast to those most commonly documented in males, which include decreased libido, sexual dysfunc-

ABBREVIATIONS ADL = activity of daily living; BDI = Beck Depression Inventory; DBS = deep brain stimulation; KPDPS = King's Parkinson's Disease Pain Scale; LEDD = levodopa equivalent daily dose; NRS = numeric rating scale; $P D=$ Parkinson's disease; $\mathrm{QOL}=$ quality of life; $r A C C=$ rostral anterior cingulate cortex; RODI = Revised Oswestry Disability Index for low-back pain; STN = subthalamic nucleus; UPDRS = Unified Parkinson's Disease Rating Scale.

SUBMITTED April 6, 2020. ACCEPTED June 8, 2020.

INCLUDE WHEN CITING Published online October 9, 2020; DOI: 10.3171/2020.6.JNS201126. 
tion, and drooling. ${ }^{5,6}$ More females than males reported pain $(41.7 \%$ vs $31.3 \%, \mathrm{p}=0.001)$. The pain was also more severe in females $(\mathrm{p}<0.001) .{ }^{5}$ A systematic review of 82 articles published between 2009 and 2016 examined nonmotor symptoms between male and female PD patients, finding similar trends in PD pain.? It is important to note, however, that this finding might not be disease specific, given the prevalence in the general population.

When considering the effects of DBS on outcomes by sex, there are considerably fewer data. A study that prospectively examined a 51-patient surgical cohort undergoing bilateral STN DBS for PD demonstrated that motor symptoms, activities of daily living (ADLs), depression, and QOL all improved equally well in females as in males; the only postoperative sex difference was less reduction of dopaminergic medications in females. ${ }^{8}$ Although these findings suggest that there may be sex differences in DBS responses, there has been a notable absence of work in DBS with specific regard to the nonmotor symptom of pain in males versus females. Here, we prospectively examined pain outcomes pre- and postoperatively following STN DBS, comparing these changes between males and females with PD.

\section{Methods}

\section{Participants}

This study prospectively examined pain outcomes in patients who underwent bilateral STN DBS placement for standard of care treatment of PD at the Albany Medical Center. The Albany Medical College IRB approved this study, with all patients having provided informed consent for prospective data collection. The patients who qualified for surgical treatment completed the Unified Parkinson's Disease Rating Scale (UPDRS) and neuropsychological testing as part of routine preoperative workup. Twenty consecutive PD patients who were evaluated for DBS implantation were included. Neuropsychological testing and UPDRS scoring in the on- and off-medication states were performed preoperatively as part of patients' routine clinical care to assess their candidacy for DBS placement. None of our subjects had dementia. Programming begins 1 month postimplantation with monopolar review and then monthly for 6 months. No data were obtained prior to optimization. Study visits were conducted on stable and optimized stimulation settings.

\section{Data Collection}

Patients completed self-reported outcome measures, detailed below, preoperatively and at a mean follow-up of 1 year. They completed a battery of pain surveys according to the standard of care preoperatively. At 6 months, 1 year, and yearly thereafter postoperatively, patients completed the surveys in accordance with an approved IRB study protocol. Patients completed questionnaires in the on-medication state preoperatively and on-medication/ stimulation state postoperatively. For the purpose of this study, we used the most recent data for analysis.

The three measures considered were the King's Parkinson's Disease Pain Scale (KPDPS), ${ }^{9}$ the numeric rating scale (NRS), and the Revised Oswestry Disability Index for low-back pain (RODI). ${ }^{10,11}$ The KPDPS is a 14-question survey that is subdivided into the following 7 domains of pain experienced in the last month due to PD or related medication: 1) musculoskeletal, 2) chronic, 3) fluctuationrelated, 4) nocturnal, 5) orofacial, 6) discoloration and edema/swelling, and 7) radicular. A subscore is obtained by multiplying severity and frequency. All domain subscores are then summed to achieve a composite score out of a total of 168. For the NRS, patients rate their pain on a scale of 0 to 10 , with 0 being no pain and 10 being the worst pain. The RODI consists of 10 questions that assess how low-back pain affects daily activities, such as personal care, lifting, walking, and sitting. Additional demographic and clinical variables obtained for each patient included sex, age at the time of surgery, duration of illness, preoperative on- and off-medication severity of motor symptoms (UPDRS-III), medications with doses and frequency, body mass index (BMI), Beck Depression Inventory (BDI), and stimulation settings, which were used in the covariate analysis. The levodopa equivalent daily dose (LEDD) was calculated using the Parkinson's Measurement Levodopa Equivalent Daily Dose Calculator (parkinsonsmeasurement.org).

Lead location classified leads as optimally placed or suboptimally placed. We routinely target $11.75 \mathrm{~mm}$ lateral, $2.5 \mathrm{~mm}$ posterior, and $5 \mathrm{~mm}$ inferior from the midcommissural point, which is appropriate in our experience based on how we typically determine the anterior commissure and posterior commissure..$^{12,13}$ Of note, we routinely use microelectrode recording and macrostimulation for all lead placements based on previously published methodology. ${ }^{12,14,15}$ Suboptimal lead placement was defined as greater than a $2-\mathrm{mm}$ distance between the intended and actual target in the $\mathrm{x}, \mathrm{y}$, or $\mathrm{z}$ coordinate system based on postoperative fusion of the preoperative MR image and postoperative CT scan.

\section{Statistical Analysis}

Differences were calculated between each score at baseline and postoperatively. Difference scores were then analyzed via nonparametric and parametric (when appropriate) unpaired-sample t-tests comparing males with females. Covariate regression analyses were run using the generalized linear model with the raw difference in survey score as the outcome variable. Further correlation analysis was run to test for a relationship between each component of stimulation settings (amplitude, frequency, pulse width, contact), and total electrical energy delivered and each outcome measure. Correlations between outcomes and all confounding variables were evaluated. We tested for normality for each analysis using the Shapiro-Wilk normality test. Parametric or nonparametric analyses were then utilized based on these results. All statistical analyses were performed in GraphPad Prism (GraphPad Software for Windows, version 8, www.graphpad.com) and IBM SPSS (IBM SPSS Statistics for Windows, version 21.0, IBM Corp.).

\section{Results \\ Demographics}

Six females and 14 males with bilateral STN DBS were 
TABLE 1. Participant demographics

\begin{tabular}{|c|c|c|c|c|c|c|c|c|c|c|}
\hline \multirow[b]{2}{*}{$\begin{array}{l}\text { Case } \\
\text { No. }\end{array}$} & \multirow{2}{*}{$\begin{array}{c}\text { Age at } \\
\text { Time of Op } \\
\text { (yrs), Sex }\end{array}$} & \multirow[b]{2}{*}{$\begin{array}{l}\text { Duration of } \\
\text { Illness (yrs) }\end{array}$} & \multirow[b]{2}{*}{$\begin{array}{c}\text { BMI } \\
\left(\mathrm{kg} / \mathrm{m}^{2}\right)\end{array}$} & \multirow[b]{2}{*}{ BDI } & \multicolumn{3}{|c|}{ UPDRS Score } & \multicolumn{3}{|c|}{ LEDD (mg) } \\
\hline & & & & & $\begin{array}{l}\text { Preop Off } \\
\text { Medication }\end{array}$ & $\begin{array}{l}\text { Preop On } \\
\text { Medication }\end{array}$ & $\%$ Change & Preop & $\begin{array}{l}\text { Postop at } \\
\text { Follow-Up }\end{array}$ & $\%$ Change \\
\hline 1 & $62, \mathrm{~F}$ & 8 & 21 & None & 33 & 15 & 55 & 900 & 1638 & 82 \\
\hline 2 & $62, \mathrm{~F}$ & 10 & 33 & Moderate depression & 33 & 13 & 61 & 775 & 563 & -27 \\
\hline 3 & $72, \mathrm{~F}$ & 6 & 36 & None & 42 & 29 & 31 & 300 & 300 & 0 \\
\hline 4 & $76, F$ & 3 & 25 & None & 53 & 15 & 70 & 1129 & 1848 & 64 \\
\hline 5 & $76, F$ & 16 & 20 & None & 25 & 3 & 90 & 250 & 4 & -98 \\
\hline 6 & $69, \mathrm{~F}$ & 13 & 24 & None & 42 & 25 & 41 & 3059 & 3124 & 2 \\
\hline 7 & $59, \mathrm{M}$ & 11 & 35 & None & 41 & 13 & 68 & 1600 & 450 & -72 \\
\hline 8 & $69, M$ & 13 & 33 & None & 37 & 27 & 27 & 1850 & 1012.5 & -45 \\
\hline 9 & $69, \mathrm{M}$ & 10 & 30 & None & 26 & 16 & 38 & 400 & 187.5 & -53 \\
\hline 10 & $55, \mathrm{M}$ & 20 & 24 & Moderate depression & 45 & 18 & 58 & 2600 & 2394 & -8 \\
\hline 11 & $52, \mathrm{M}$ & 10 & 29 & Mild depression & 27 & 5 & 81 & 1050 & 1075 & 2 \\
\hline 12 & $60, M$ & 10 & 26 & Mild depression & 32 & 5 & 84 & 550 & 625 & 14 \\
\hline 13 & $47, M$ & 19 & 48 & None & 42 & 22 & 48 & 400 & 125 & -69 \\
\hline 14 & $68, M$ & 8 & 32 & Mild depression & 34 & 15 & 56 & 1595 & 1000 & -37 \\
\hline 15 & $59, \mathrm{M}$ & 20 & 28 & None & 44 & 24 & 46 & 3264 & 925 & -72 \\
\hline 16 & $68, M$ & 9 & 20 & None & 46 & 30 & 35 & 1087.5 & 62.5 & -94 \\
\hline 17 & $62, \mathrm{M}$ & 10 & 24 & None & 49 & 35 & 30 & 2743 & 935 & -66 \\
\hline 18 & $56, \mathrm{M}$ & 7 & 30 & Mild depression & 36 & 14 & 61 & 1215 & 375 & -69 \\
\hline 19 & $71, \mathrm{M}$ & 20 & 26 & None & 54 & 17 & 69 & 2930 & 1762.5 & -40 \\
\hline 20 & $58, \mathrm{M}$ & 14 & 28 & None & 46 & 9 & 80 & 2000 & 427 & -79 \\
\hline
\end{tabular}

enrolled in this study and completed each outcome measure preoperatively and at a mean of 11.8 months (range 6-42 months) postoperatively. The mean follow-up for males was 10 months (range 6-23 months), and for females it was 16 months (range 6-42 months). The followup time was not significantly different between the two cohorts $(\mathrm{p}=0.32)$. The mean patient age at the time of surgery was 64.8 years (range 29-77 years). Females were significantly older than males at the time of surgery $(\mathrm{p}=$ 0.02 ; mean \pm SEM females, $69.5 \pm 2.6$ years; and males, $60.9 \pm 1.9$ years). Demographics, including sex, age at time of surgery, duration of illness, preoperative severity of motor symptoms (UPDRS-III), LEDD, BMI, and BDI results, are shown in Table 1. No patients had diabetes mellitus, and review of lumbar MR images showed limited pathology. Lead coordinates and stimulation settings are shown in Table 2.

Covariate analyses showed no effects of patient age, duration of disease, percentage improvement of preoperative on- and off-medication UPDRS-III scores, or preand postoperative LEDD on outcomes. Male LEDD was significantly reduced by $45 \%$ postoperatively $(\mathrm{p}<0.001)$, while female doses were only reduced by $4 \%(\mathrm{p}=0.62)$. However, there was no significant difference between male LEDD percentage change and female LEDD percentage change $(p=0.08)$. The percentage improvement in preoperative UPDRS-III on- and off-medication scores was not significantly different between males and females $(\mathrm{p}=$ 0.82 ). While females were significantly older than males, covariate analysis showed no effect of age on any outcome measure. We found no correlation between sex and depression or age and depression. Patients with less depression according to the BDI had greater improvement in pain on the NRS $(p=0.01, r=-0.56)$. Interestingly, patients who were more depressed had greater improvement in fluctuation-related pain $(\mathrm{p}=0.02, \mathrm{r}=0.53)$. Potentially, this finding can be explained if depression was related to changes of living with chronic disease that were relieved when activity and QOL were restored. This remains hypothetical at this point. Patients with a higher BMI showed less improvement in domain 6 (discoloration and edema/swelling) according to the KPDPS score $(\mathrm{p}=0.03, \mathrm{r}=-0.48)$. Eleven of our 20 patients had lumbar MRI scans ( 4 of 6 females and 7 of 14 males). Only 1 male had clinically significant findings of significant degenerative scoliosis. One woman had a history of spinal fusion.

\section{Pain Outcomes}

Male KPDPS total scores significantly decreased from $15.7 \pm 3.1$ preoperatively to $6.0 \pm 1.9$ postoperatively $(\mathrm{p}<$ $0.001)$. Specifically, males demonstrated improvement in fluctuation pain (from $4.5 \pm 1.1$ to $1.1 \pm 0.57, \mathrm{p}=0.008$ ) and showed a trending improvement in nocturnal pain (from $4.4 \pm 1.2$ to $1.1 \pm 0.4, p=0.07$ ). Neither total nor specific domain KPDPS scores decreased significantly in females. Comparatively, males showed significantly greater improvement after DBS than females in musculoskeletal pain (males, $1.2 \pm 0.7$; females, $-1.8 \pm 1.1 ; \mathrm{p}=0.03$ ) and chronic pain (males, $1.0 \pm 0.7$; females, $-2.5 \pm 1.2 ; \mathrm{p}=$ 0.01 ; Fig. 1). There were no differences between sexes in 
TABLE 2. DBS coordinates for center of bottom contact relative to midcommissural point

\begin{tabular}{|c|c|c|c|c|c|c|c|}
\hline \multirow{2}{*}{$\begin{array}{l}\text { Case } \\
\text { No. }\end{array}$} & \multicolumn{3}{|c|}{ Lt Lead Coordinates (mm) } & \multicolumn{3}{|c|}{ Rt Lead Coordinates (mm) } & \multirow{2}{*}{$\begin{array}{l}\text { Stimulation Settings } \\
\text { at Follow-Up }(\mathrm{A} / \mu \mathrm{sec} / \mathrm{Hz})\end{array}$} \\
\hline & Lateral & Posterior & Inferior & Lateral & Posterior & Inferior & \\
\hline 1 & 10.11 & 4.41 & 1.35 & 9.47 & 0.80 & 6.82 & Lt [1+2-] 3.5/60/60; rt [9+10-] 3.1/60/60 \\
\hline 2 & 11.21 & 2.38 & 5.30 & 9.70 & 3.57 & 3.90 & Lt [C+0-] 2.0/60/150; rt [C+8-] 2.4/60/150 \\
\hline 3 & 12.43 & 1.44 & 6.82 & 10.20 & 2.15 & 5.76 & Rt $[C+10 a b-11 b-] 1.1 / 40 / 130 ;$ It $[C+2 b-3 b-] 1.1 / 40 / 110$ \\
\hline 4 & 10.03 & 2.26 & 5.08 & 11.64 & 5.28 & 2.09 & $\mathrm{Lt}[\mathrm{C}+1-]$ 1.1/90/130; rt [C+9-] 4.6/90/130 \\
\hline 5 & 11.79 & 1.48 & 2.99 & 12.02 & 2.61 & 3.27 & Lt [C+1-] 2.6/90/160; rt [C+9-] 2.1/40/130 \\
\hline 6 & 12.02 & 1.56 & 5.40 & 11.59 & 4.50 & 3.28 & Lt [C+2B-] 3.2/60/160; rt [C+9-] 2.45/60/130 \\
\hline 7 & 10.11 & 3.67 & 6.75 & 10.16 & 4.70 & 5.26 & Lt [C+0-] 1.3/70/130; rt [C+8-] 2.0/80/130 \\
\hline 8 & 11.41 & 3.68 & 5.49 & 10.11 & 4.65 & 4.06 & Lt [C+1-] 3.9/60/90; rt [C+9-] 2.8/60/90 \\
\hline 9 & 11.47 & 2.04 & 4.50 & 12.12 & 0.39 (anterior) & 5.33 & Lt [C+0-] 4.0/60/160; rt [C+8-] 4.2/60/160 \\
\hline 10 & 10.61 & 2.10 & 3.56 & 10.07 & 2.55 & 6.45 & $\mathrm{Lt}[\mathrm{C}+0-] 2.0+/-1.0 / 60 / 170 ; \mathrm{rt}[\mathrm{C}+10-] 1.9+/-1.0 / 60 / 170$ \\
\hline 11 & 11.26 & 1.04 & 5.02 & 11.36 & 4.70 & 3.93 & Lt [C+2-] 2.4/60/130; rt [C+10A-10C-] 2.6/60/130 \\
\hline 12 & 11.05 & 1.90 & 6.27 & 8.58 & 3.70 & 7.10 & Lt [C+3-] 1.3/90/135; rt [C+10-] 1.4/60/150 \\
\hline 13 & 11.90 & 2.84 & 2.24 & 8.57 & 3.26 & 0.83 (superior) & Lt [C+1-] 1.4/80/130; rt [C+8-] 1.5/80/130 \\
\hline 14 & 12.75 & 0.90 & 4.27 & 9.27 & 3.55 & 4.20 & Lt [C+3-] 2.8/60/160; rt [C+11-] 3.0/60/130 \\
\hline 15 & 12.34 & 1.00 & 5.11 & 11.23 & 3.40 & 3.40 & Lt [C+2-] 1.5/30/130; rt [C+10-] 2.5/60/130 \\
\hline 16 & 11.65 & 2.39 & 4.96 & 10.07 & 3.58 & 4.04 & Lt [C+2-] 2.5/70/160; rt [C+11-] 3.9/70/160 \\
\hline 17 & 10.06 & 3.55 & 4.56 & 10.93 & 4.44 & 3.96 & Lt [C+2-] 3.00/60/160; rt [C+11-] 3.00/60/160 \\
\hline 18 & 12.66 & 1.92 & 4.14 & 11.24 & 1.22 & 4.74 & Lt [C+2A-2B-] 3.8/60/130; rt [C+1-2-] 4.35/60/130 \\
\hline 19 & 12.01 & 1.45 & 5.13 & 11.22 & 2.77 & 3.98 & Lt [C+1-] 3.70/90/160; rt [C+9-] 3.10/60/160 \\
\hline 20 & 12.19 & 1.26 & 2.61 & 11.03 & 2.01 & 3.31 & Lt [C+1-] 2.3/80/130; rt [C+10-] 3.4/70/140 \\
\hline
\end{tabular}

Values in boldface type indicate suboptimally placed leads.

total score $(\mathrm{p}=0.16)$ or other domains (fluctuation-related pain, $\mathrm{p}=0.65$; nocturnal pain, $\mathrm{p}=0.39$; orofacial pain, $\mathrm{p}$ $=0.88$; discoloration, $\mathrm{p}=0.36$; radicular pain, $\mathrm{p}=0.89$ ).

Both male and female RODI scores improved. Male scores significantly decreased by $52 \%$ (from $17.9 \pm 3.6$ to $8.6 \pm 1.6, \mathrm{p}=0.03$ ), while female scores decreased by $30 \%$ (from $23.3 \pm 8.0$ to $16.2 \pm 4.8, \mathrm{p}=0.30$ ). Comparatively, however, there were no differences in improvements between sexes $(\mathrm{p}=0.77)$. Male and female NRS scores also improved between baseline and postoperative follow-up. Male scores decreased by $100 \%$ (from $0.57 \pm 0.4$ to $0 \pm 0$, $\mathrm{p}=0.48$ ), and female scores decreased by $11 \%$ (from $1.5 \pm$ 0.7 to $1.3 \pm 1.3, p>0.99$; Fig. 2). There were no significant differences between sexes $(\mathrm{p}>0.99)$.

\section{Correlations Between DBS Settings and Outcomes}

When we evaluated outcomes based on the classification of lead location, we found no significant difference in KPDPS total or the domains, RODI ( $p=0.90)$, or NRS ( $p$ $>0.99$ ). There were no differences in the number of suboptimally placed leads in the male and female cohorts $(\mathrm{p}=$ $0.64)$. There was no significant difference between males and females in frequency $(p=0.58$ and $p=0.10$, left and right, respectively), pulse width ( $\mathrm{p}=0.72$ and $\mathrm{p}=0.30$, left and right, respectively), amplitude ( $\mathrm{p}=0.39$ and $\mathrm{p}=0.87$, left and right, respectively), or total electrical energy delivered $(p=0.69$ and $p=0.75$, left and right, respectively). In males, the KPDPS total scores negatively correlated with left pulse width $(\mathrm{p}=0.01, \mathrm{r}=-0.6$; lower pulse width correlated with less pain). NRS negatively correlated with left frequency $(\mathrm{p}=0.03, \mathrm{r}=-0.6)$ and right frequency $(\mathrm{p}=$ $0.02, r=-0.6$; lower frequency correlated with less pain). There were no correlations between stimulation settings and outcomes in females.

\section{Discussion}

In this study, we prospectively evaluated whether the effects of STN DBS on PD pain are influenced by patient sex. Our data demonstrate that STN DBS improved total KPDPS and RODI scores in males. KPDPS musculoskeletal and chronic pain improved more in men than in women. According to the NRS, the improvements seen in both sexes were not significant. These data suggest that $\mathrm{PD}$ pain may be more responsive to STN DBS in males than in females. We also demonstrated that there was a significant reduction in LEDD in males but not in females, which is consistent with the literature, showing that women had significantly less reduction in LEDD after 1 year of bilateral STN DBS compared with their male counterparts. ${ }^{8}$

Past studies assessing the effects of sex on STN DBS have focused more on the motor symptoms of PD. One study followed 158 PD patients for a mean of $15.4 \pm 11.0$ months and demonstrated that male sex was a positive predictor for significant improvement in camptocormia after bilateral STN DBS. ${ }^{16}$ In addition, a 5-year study that prospectively examined differences in adverse effects between 11 males and 9 females indicated that females experience more persistent motor adverse effects, particularly hypophonia and eyelid-opening apraxia, that did not 
Domain 1: Musculoskeletal Pain

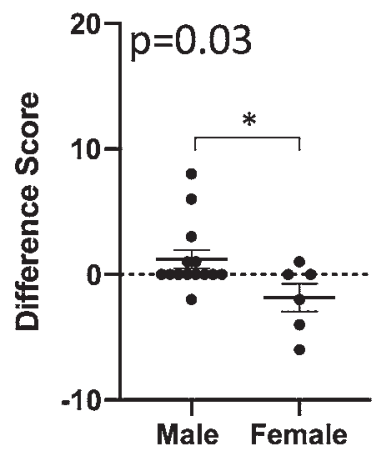

Domain 4: Nocturnal Pain

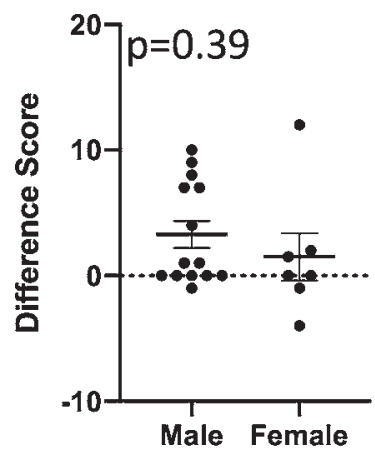

Domain 7: Radicular Pain

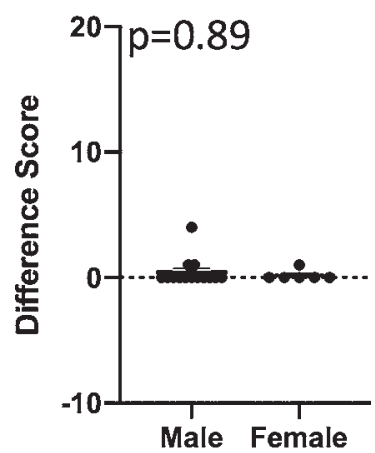

Domain 2: Chronic Pain

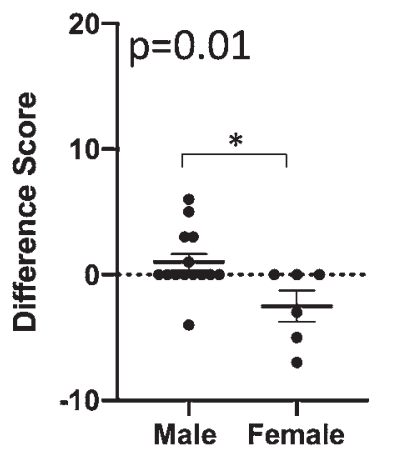

Domain 5: Oro-facial Pain

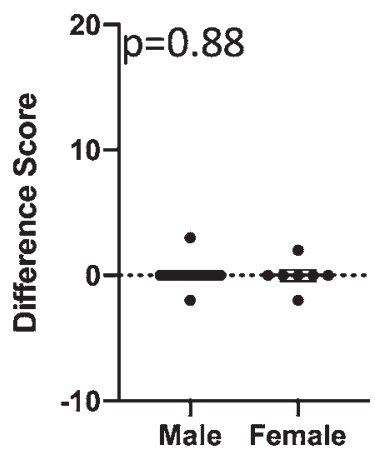

Total

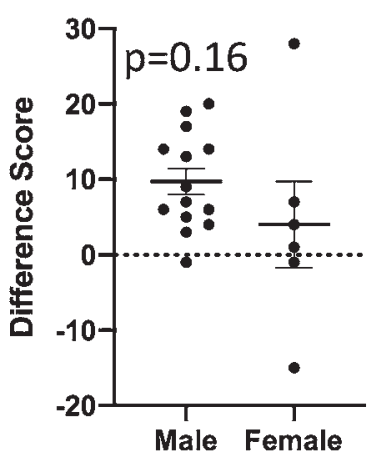

Domain 3: Fluctuation-related Pain

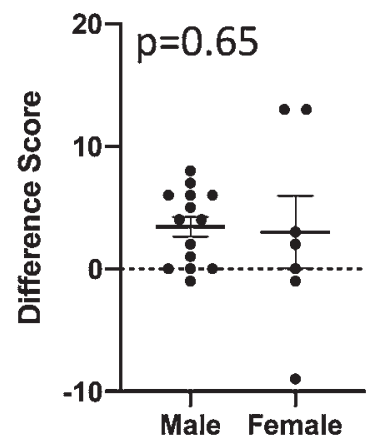

Domain 6: Discoloration; Edema

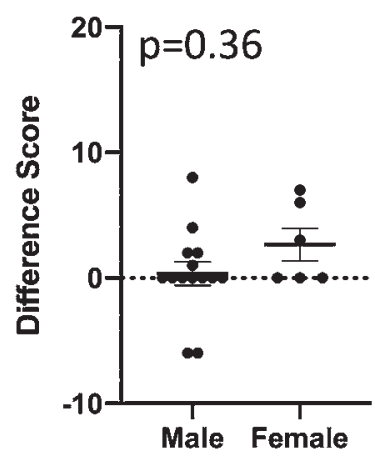

FIG. 1. Differences in KPDPS scores between males and females. Data are plotted as the mean \pm SEM of total KPDPS scores and domains in both the male and female cohorts. There were significant differences in musculoskeletal pain $(p=0.03)$ and chronic pain $(p=0.01)$. The $y$-axis on the "Total" graph has been extended to show the outliers in the female cohort. improve after stimulation was turned off for a short period time; adverse effects in the males were more often transient. ${ }^{17}$ Another study on 48 males and 24 females with bilateral STN DBS retrospectively identified differences between sexes in prognostic factors for improvements in resting tremor, ADLs, and levodopa-induced dyskinesia at the 6-month follow-up. Preoperatively, lower levodopa requirements and a more severe tremor were positive prognostic factors in males, while higher ADL functioning and improvements in akinesia after levodopa therapy were positive prognostic factors in females. ${ }^{18}$

Sex differences on short- and long-term effects of STN DBS in PD were investigated in another study, by Kim et al., who prospectively analyzed pre- and postoperative responses in males versus females. They assessed motor function, ADLs, QOL, cognitive function, and depression 1 and 5 years postoperatively. ${ }^{19}$ Equal responses were seen in both groups with the exception of QOL, which improved more in males at both follow-up time points. Of note, QOL was also reported to be higher in patients without musculoskeletal problems in another cross-sectional study evaluating QOL in 400 PD patients. ${ }^{20}$ Our results add to these findings by showing that musculoskeletal pain after STN DBS was significantly improved in males, which may account for the previously reported higher QOL. ${ }^{19}$

Further consideration of our findings invites the following question: why does the difference in pain response exist between sexes? Several studies on this topic have shown evidence for increased pain sensitivity and ratings, as well as lower pain tolerance to quantitative sensory testing in 

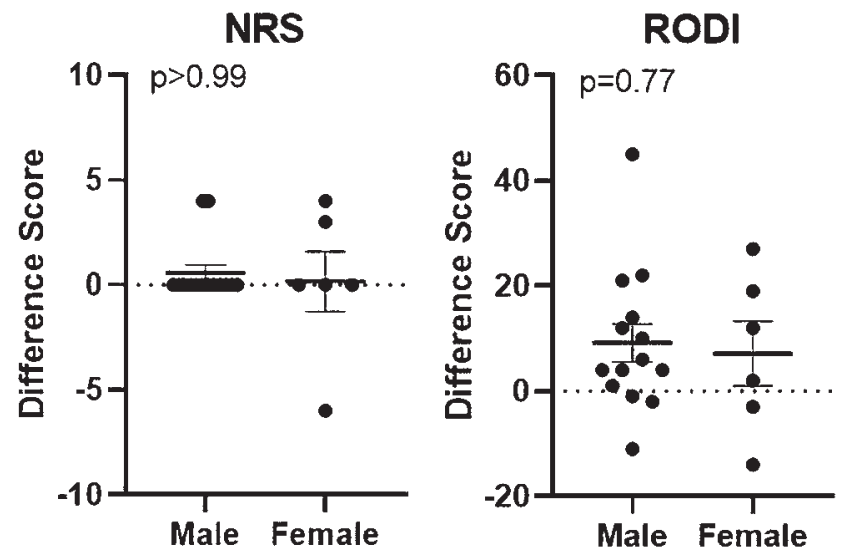

FIG. 2. Differences in NRS and RODI scores between males and females. Data are plotted as mean \pm SEM of total NRS scores (left) and total RODI scores (right) in both the male and female cohorts. There were no significant differences between males and females in NRS difference scores $(p>0.99)$ or RODI difference scores $(p=0.77)$.

females compared with males. ${ }^{21}$ Several theories have been proposed for the differences in pain thresholds between males and females at the cellular level-hormonal differences, sex-specific upregulation of ion channels in the dorsal root ganglion, and differences in inflammatory factors, pain signal transduction, and endogenous opioid analgesia-many or all of which could be true and simultaneously contributing to the overall pain experience. Mouse models have proven that social interaction plays a large part in pain modulation and analgesia, with evidence indicating that females are more likely to utilize and benefit from social interaction when in pain, which has measurable effects on pain behavior. ${ }^{21} \mathrm{~A}$ literature review by Sorge and Totsch found that, in rodent models, spinal cord microglia are the main mediators of chronic pain in males, while females rely most strongly on T-cells, ${ }^{22}$ potentially giving some explanation for disproportionate chronic pain symptoms between males and females. Multiple studies have examined sex differences in innate and adaptive immune responses in rodents associated with various disease states, with findings indicating that female rodents display higher expression of genes involved in acute-phase and inflammatory responses, larger T-cell populations, and greater macrophage numbers than males. ${ }^{23-25}$

Rosen et al. ${ }^{26}$ discussed how chronic pain often is a result of inflammation or nerve damage, both instances where females tend to be more susceptible. Immune responses to tissue damage have been shown to be much more significant in females than in males, suggesting that with more inflammation comes more pain. If this process is maintained long-term, this chronic inflammatory pain may also result in sensitization of peripheral nociceptors, further contributing to the maintenance of the inflammatory pain cycle. ${ }^{26}$ Inflammation also plays a role in PD pathophysiology, as inflammatory activation of glial cells is believed to contribute to progressive neurodegeneration. Regarding the effects of STN DBS on the inflammatory processes involved in PD and pain, a study showed that STN DBS reverses increased levels of inflammatory markers interferon- $\gamma$ and interleukin-10 in the globus pallidus, an output nucleus of the STN, of 6-hydroxydopamine-lesioned parkinsonian male rats. ${ }^{27}$

Sex differences in PD include a higher incidence in males at a ratio of 1.6:1 and later onset of disease in females. ${ }^{6}$ Females also have a higher rate of drug-related motor phenomena, especially levodopa-induced dyskinesia and wearing off. ${ }^{7}$ In addition, a prospective study that followed 47 de novo, drug-naive PD patients (16 female and 31 male) for 4 years postdiagnosis demonstrated that fluctuations in nonmotor symptoms in the form of pain, mood changes, and anxiety were more common in females. ${ }^{28}$ A later disease onset also logically translates to increased risk for the presence of pathologies associated with pain as a result of joint degeneration and other agerelated processes.

The mechanism for the therapeutic effects of STN DBS on PD-related pain remains unclear but most likely involves the descending inhibitory pain pathway. The descending inhibitory pain pathway involves connections between the rostral anterior cingulate cortex (rACC), periaqueductal gray, and rostroventromedial medulla. ${ }^{29}$ Authors who performed FDG PET in 8 PD patients before and 4 months after bilateral STN DBS implantation notably showed increased glucose metabolism in the ACC, thereby suggesting that the ACC is involved in the mechanism of STN DBS. ${ }^{30,31}$ Interestingly, the aforementioned rACC was found to have significantly increased functional connectivity to the dorsal dysgranular insula in males. This was elucidated in a study that used functional MRI to analyze differences in functional connectivity between the insula, a structure associated with pain processing, and the rest of the brain; the sample included 37 healthy individuals (26 males and 11 females) with an approximate average age of 50 years, which is close to the average age of onset for PD. ${ }^{32}$ These findings suggest that the rACC that is potentially involved in the mechanism of STN DBS may account for more pain reduction in males than females.

In our cohort, females were significantly older than males. It is unclear how this affects the data, but it should be noted that the cognitive dimension of pain may worsen with age. ${ }^{33} \mathrm{PD}$ is further complicated by differences in the disease course between males and females. While $\mathrm{PD}$ is more prevalent in males, disease progresses further in females,$^{34}$ and LEDDs tend to increase in females to a greater extent over time..$^{35}$ Research has not extensively investigated the effect of age in PD. However, when we look at the literature, PD patients who report pain are a mean age of 69 years ${ }^{36-39}$ which is slightly older than the average age of onset of PD (62 years)..$^{40}$ However, pain can also be a portion of the prodrome of PD. ${ }^{41}$ Regardless, pain remains underreported in this group, as $40 \%$ of PD patients with chronic pain do not report it in their visits. ${ }^{42} \mathrm{~A}$ larger series is needed to parse out the effects.

Our data showing the greater efficacy of STN DBS for pain reduction in males may be explained by sex-specific modulation of brain structures involved in pain perception. Furthermore, another study with 12 males and 12 females indicated that the STN target itself exhibits gender dimorphism. ${ }^{43} \mathrm{~A}$ few days after bilateral STN DBS implantation, local field potentials were recorded before and then after dopaminergic drug administration. Females displayed a significantly higher power in the alpha/low-beta band 
$(13-20 \mathrm{~Hz})$ and high-gamma band $(60-90 \mathrm{~Hz})$ before and after drug administration, respectively. ${ }^{43}$ These innate differences in the STN may account for sex differences in the effects of different settings on outcomes, as demonstrated in a study by Belasen et al. ${ }^{44}$ Their study examined 19 patients with PD-associated chronic pain receiving STN DBS and found that females were significantly sensitive to pressure pain and less sensitive to mechanical pain with both high-frequency and low-frequency stimulation.

We acknowledge the limitations of this study. Our analysis would benefit from more female participants and an overall larger sample size. There are innate limitations of self-reported questionnaires, and their results can be subject to day-to-day symptom variability, boredom, distraction, and mental fatigue ${ }^{45}$ Furthermore, there are many other factors in pain processing that preclude a simple conclusion about the mechanism of DBS in pain control. These include the multitude of physiological and pathophysiological mechanisms involved in pain processing, differences in pain threshold due to sensory versus affective processing, and pain modality (i.e., mechanical or thermal). ${ }^{46}$ Additionally, we acknowledge that there was a significant difference in age between the male and female groups. While covariate analysis showed that age did not have an effect on the outcome measures, our study would be strengthened with a more even distribution of patient age. Other potential confounding variables for pain that we did not investigate in the two groups are over-the-counter and prescribed pain medications, substance use such as alcohol or cannabis, sleep measures, mood measures, and mental health history. Despite our small sample size, we find our results compelling enough to counsel female patients with PD that their pain is less likely to improve following DBS. It is our hope that a larger follow-up study will yield more generalizable results.

\section{Conclusions}

Here, we prospectively examined sex differences between pain outcomes following STN DBS for PD. Males had improvements in total and musculoskeletal KPDPS scores. They also showed significantly greater improvement after DBS than females in KPDPS domains of musculoskeletal pain and chronic pain. Both males and females had less low-back disability following DBS. Although it is well recognized that pain complaints in PD differ in men and women, this study is unique in its prospective assessment of sex-specific DBS effects on this symptom. Considering sex as a biological variable may have important implications for DBS pain outcome studies moving forward.

\section{References}

1. Moro E, Lozano AM, Pollak P, et al. Long-term results of a multicenter study on subthalamic and pallidal stimulation in Parkinson's disease. Mov Disord. 2010;25(5):578-586.

2. Zesiewicz TA, Sullivan KL, Hauser RA. Nonmotor symptoms of Parkinson's disease. Expert Rev Neurother. 2006; 6(12):1811-1822.

3. Chaudhuri KR, Healy DG, Schapira AHV. Non-motor symptoms of Parkinson's disease: diagnosis and management. Lancet Neurol. 2006;5(3):235-245.

4. Valkovic P, Harsany J, Hanakova M, et al. Nonmotor symptoms in early- and advanced-stage Parkinson's disease patients on dopaminergic therapy: how do they correlate with quality of life? ISRN Neurol. 2014;2014:587302.

5. Martinez-Martin P, Falup Pecurariu C, Odin P, et al. Genderrelated differences in the burden of non-motor symptoms in Parkinson's disease. J Neurol. 2012;259(8):1639-1647.

6. Zagni E, Simoni L, Colombo D. Sex and gender differences in central nervous system-related disorders. Neurosci J. 2016; 2016:2827090.

7. Georgiev D, Hamberg K, Hariz M, et al. Gender differences in Parkinson's disease: a clinical perspective. Acta Neurol Scand. 2017;136(6):570-584.

8. Chandran S, Krishnan S, Rao RM, et al. Gender influence on selection and outcome of deep brain stimulation for Parkinson's disease. Ann Indian Acad Neurol. 2014;17(1):66-70.

9. Chaudhuri KR, Rizos A, Trenkwalder C, et al. King's Parkinson's disease pain scale, the first scale for pain in PD: an international validation. Mov Disord. 2015;30(12):1623-1631.

10. Fairbank JC, Couper J, Davies JB, O'Brien JP. The Oswestry low back pain disability questionnaire. Physiotherapy. 1980; 66(8):271-273.

11. Hudson-Cook N, Tomes-Nicholson K, Breen A. A revised Oswestry disability questionnaire. In: Roland MO, Jenner JR, eds. Back Pain: New Approaches to Rehabilitation and Education. Manchester University Press, 1989:187-204.

12. Przybyszewski AW, Ravin P, Pilitsis JG, et al. Multi-parametric analysis assists in STN localization in Parkinson's patients. J Neurol Sci. 2016;366:37-43.

13. Rashid T, Hwang R, DiMarzio M, et al. Evaluating the role of $1.5 \mathrm{~T}$ quantitative susceptibility mapping for subthalamic nucleus targeting in deep brain stimulation surgery. $J$ Neuroradiol. Published online May 28, 2019. doi:10.1016/j. neurad 2019.04.007

14. Novak P, Przybyszewski AW, Barborica A, et al. Localization of the subthalamic nucleus in Parkinson disease using multiunit activity. J Neurol Sci. 2011;310(1-2):44-49.

15. Peng S, Levine D, Ramirez-Zamora A, et al. A comparison of unilateral deep brain stimulation (DBS), simultaneous bilateral DBS, and staged bilateral DBS lead accuracies. Neuromodulation. 2017;20(5):478-483.

16. Roediger J, Artusi CA, Romagnolo A, et al. Effect of subthalamic deep brain stimulation on posture in Parkinson's disease: a blind computerized analysis. Parkinsonism Relat Disord. 2019;62:122-127.

17. Romito LM, Contarino FM, Albanese A. Transient gender-related effects in Parkinson's disease patients with subthalamic stimulation. J Neurol. 2010;257(4):603-608.

18. Chiou SM. Sex-related prognostic predictors for Parkinson disease undergoing subthalamic stimulation. World Neurosurg. 2015;84(4):906-912.

19. Kim R, Yoo D, Choi JH, et al. Sex differences in the shortterm and long-term effects of subthalamic nucleus stimulation in Parkinson's disease. Parkinsonism Relat Disord. 2019;68:73-78.

20. Kim YE, Kim HJ, Yun JY, et al. Musculoskeletal problems affect the quality of life of patients with Parkinson's disease. J Mov Disord. 2018;11(3):133-138.

21. Mogil JS. Sex differences in pain and pain inhibition: multiple explanations of a controversial phenomenon. Nat Rev Neurosci. 2012;13(12):859-866.

22. Sorge RE, Totsch SK. Sex differences in pain. J Neurosci Res. 2017;95(6):1271-1281.

23. Legorreta-Herrera M, Mosqueda-Romo NA, Nava-Castro $\mathrm{KE}$, et al. Sex hormones modulate the immune response to Plasmodium berghei ANKA in CBA/Ca mice. Parasitol Res. 2015;114(7):2659-2669.

24. Xiong X, Xu L, Wei L, et al. IL-4 is required for sex differences in vulnerability to focal ischemia in mice. Stroke. 2015; 46(8):2271-2276. 
25. Cabello N, Mishra V, Sinha U, et al. Sex differences in the expression of lung inflammatory mediators in response to ozone. Am J Physiol Lung Cell Mol Physiol. 2015;309(10): L1150-L1163.

26. Rosen S, Ham B, Mogil JS. Sex differences in neuroimmunity and pain. $J$ Neurosci Res. 2017;95(1-2):500-508.

27. Campos ACP, Kikuchi DS, Paschoa AFN, et al. Unraveling the role of astrocytes in subthalamic nucleus deep brain stimulation in a Parkinson's disease rat model. Cell Mol Neurobiol. 2020;40(6):939-954.

28. Picillo M, Palladino R, Moccia M, et al. Gender and non motor fluctuations in Parkinson's disease: a prospective study. Parkinsonism Relat Disord. 2016;27:89-92.

29. Ossipov MH, Morimura K, Porreca F. Descending pain modulation and chronification of pain. Curr Opin Support Palliat Care. 2014;8(2):143-151.

30. Hilker R, Voges J, Weisenbach S, et al. Subthalamic nucleus stimulation restores glucose metabolism in associative and limbic cortices and in cerebellum: evidence from a FDGPET study in advanced Parkinson's disease. J Cereb Blood Flow Metab. 2004;24(1):7-16.

31. Albaugh DL, Shih YY. Neural circuit modulation during deep brain stimulation at the subthalamic nucleus for Parkinson's disease: what have we learned from neuroimaging studies? Brain Connect. 2014;4(1):1-14.

32. Dai YJ, Zhang X, Yang Y, et al. Gender differences in functional connectivities between insular subdivisions and selective pain-related brain structures. J Headache Pain. 2018; 19(1):24.

33. Schofield P. Pain in older adults: epidemiology, impact and barriers to management. Rev Pain. 2007;1(1):12-14.

34. Cerri S, Mus L, Blandini F. Parkinson's disease in women and men: What's the difference? J Parkinsons Dis. 2019;9(3): 501-515.

35. Colombo D, Abbruzzese G, Antonini A, et al. The "gender factor" in wearing-off among patients with Parkinson's disease: a post hoc analysis of DEEP study. ScientificWorldJournal. 2015;2015:787451.

36. Beiske AG, Loge JH, Rønningen A, Svensson E. Pain in Parkinson's disease: prevalence and characteristics. Pain. 2009; 141(1-2):173-177.

37. Nègre-Pagès L, Regragui $\mathrm{W}$, Bouhassira $\mathrm{D}$, et al. Chronic pain in Parkinson's disease: the cross-sectional French DoPaMiP survey. Mov Disord. 2008;23(10):1361-1369.

38. Defazio G, Berardelli A, Fabbrini G, et al. Pain as a nonmotor symptom of Parkinson disease: evidence from a casecontrol study. Arch Neurol. 2008;65(9):1191-1194.

39. Broetz D, Eichner M, Gasser T, et al. Radicular and nonradicular back pain in Parkinson's disease: a controlled study. Mov Disord. 2007;22(6):853-856.

40. Rustøen T, Wahl AK, Hanestad BR, et al. Age and the experience of chronic pain: differences in health and quality of life among younger, middle-aged, and older adults. Clin J Pain. 2005;21(6):513-523.
41. Gaenslen A, Swid I, Liepelt-Scarfone I, et al. The patients' perception of prodromal symptoms before the initial diagnosis of Parkinson's disease. Mov Disord. 2011;26(4):653-658.

42. Chaudhuri KR, Prieto-Jurcynska C, Naidu Y, et al. The nondeclaration of nonmotor symptoms of Parkinson's disease to health care professionals: an international study using the nonmotor symptoms questionnaire. Mov Disord. 2010;25(6): 704-709.

43. Marceglia S, Mrakic-Sposta S, Foffani G, et al. Gender-related differences in the human subthalamic area: a local field potential study. Eur J Neurosci. 2006;24(11):3213-3222.

44. Belasen A, Rizvi K, Gee LE, et al. Effect of low-frequency deep brain stimulation on sensory thresholds in Parkinson's disease. J Neurosurg. 2017;126(2):397-403.

45. Siao P, Cros DP. Quantitative sensory testing. Phys Med Rehabil Clin N Am. 2003;14(2):261-286.

46. Marques A, Chassin O, Morand D, et al. Central pain modulation after subthalamic nucleus stimulation: a crossover randomized trial. Neurology. 2013;81(7):633-640.

\section{Disclosures}

Dr. Sukul is a consultant for Boston Scientific and Medtronic. Dr. Durphy is on the speaker's bureau and is a member of the working group for Acorda Pharmaceuticals. Dr. Hanspal is supported by the Dake Chair. Dr. Adam has served as a consultant for Abbott. Dr. Molho is supported by the Riley Family Chair in Parkinson's Disease; he receives consulting fees from Neurocrine Biosciences; he receives grant support from CHDI/ HSG, Civitas Therapeutics, MJF/PSG, and Biogen; and he is on the Neurocrine Biosciences speaker's bureau. Dr. Pilitsis is a consultant for Boston Scientific, Nevro, TerSera, and Abbott and receives grant support from Medtronic, Boston Scientific, Abbott, Nevro, TerSera, and NIH (grant nos. 2R01CA166379-06 and NIH U44NS115111); and she is a medical advisor for and has stock equity in Aim Medical Robotics and Karuna.

\section{Author Contributions}

Conception and design: Pilitsis. Acquisition of data: Khazen, DiMarzio, Platanitis, Hancu. Analysis and interpretation of data: Pilitsis, Khazen, DiMarzio, Platanitis. Drafting the article: Khazen, Platanitis, Grimaudo, Hancu, Shao, Staudt. Critically revising the article: Pilitsis, Khazen, Grimaudo, Maguire, Sukul, Durphy, Hanspal, Adam, Molho. Reviewed submitted version of manuscript: Pilitsis, Grimaudo, Hancu, Shao, Staudt, Maguire, Sukul, Durphy, Hanspal, Adam, Molho. Approved the final version of the manuscript on behalf of all authors: Pilitsis. Statistical analysis: Khazen, DiMarzio. Administrative/technical/material support: Pilitsis, Khazen. Study supervision: Pilitsis.

\section{Correspondence}

Julie G. Pilitsis: Albany Medical College, Albany, NY.jpilitsis@ yahoo.com. 